About rescues, reviews and dissents.

From the existentialism to the postmodernity

\title{
Sobre rescates, revisiones y disidencias. Del existencialismo a la postmodernidad
}

Ana Isabel Hernández Rodríguez.

\author{
ana.isabel.her.rod@gmail.com \\ Elisa J. Pérez Rosales \\ elisarosales6721@gmail.com
}

DOI: https://doi.org/10.15366/bp.2020.24.010

Bajo Palabra. II Época. № 24. Pgs: 197-212

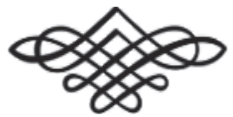


Recibido: 13/08/2018

Aprobado: 28/07/2020

Resumen

Este artículo analiza de una manera combinatoria algunos elementos de la filosofía existencialista prestando una atención especial a los planteamientos de Jean-Paul Sartre, Maurice Merleau-Ponty y Simone de Beauvoir. Se trata de demostrar cómo el utillaje conceptual existencialista puede ser (re)actualizado por algunas vertientes de pensamiento postmoderno. El fin es articular un llamamiento a la liberación inexcusable de la humanidad, pero allende los intentos filosóficos de dejar atrás la determinación de la corporalidad, la situación o el contexto. Tal es el caso del pensamiento de Judith Butler a través de la radicalización de algunas nociones del feminismo de Beauvoir.

Palabras clave:Libertad, situación, sujeto, cuerpo, existencia.

\section{Abstract}

This article analyzes in a combinatorial way some elements of the existentialist philosophy giving a special attention to the approaches of Jean-Paul Sartre, Maurice Merleau-Ponty and Simone de Beauvoir. The aim is to demonstrate how the existentialist conceptual tools can be (re)updated by some slopes of the postmodern thought. The purpose is to articulate a call to the inexcusable liberation of the humanity, but beyond the philosophical attempts of leaving behind the determination of the corporeality, the situation or the context. Such is the case of Judith Butler's thought through the radicalization of some notions of Beauvoir's feminism.

Keywords: Freedom, situation, subject, body, existence. 


\section{Introducción}

De Simone de Beauvoir destacan muchas cosas. Entre ellas, la preconfiguración de ciertas conceptualizaciones postmodernas, como la de Judith Butler, pues de su pluma brotó el afán de recurrir a la narratividad como expediente de sentido. Inmersas, de una manera irremisible y reconocida, en la propia existencia, podemos entrever con Beauvoir y Butler cómo la filosofía y la literatura adolecen, o más bien gozan, de una inestabilidad y movilidad que es característica de las travesías humanas: ambigüedad por las que tales travesías se definen como libres. Dado esto, resulta paradójico el olvido contemporáneo del existencialismo, toda vez que esta filosofía nunca pretendió despegarse del autobiografismo ${ }^{1}$.

Como sabemos, Beauvoir articuló una noción de mujer exenta de primados esencialistas, esto es, como devenir cultural y no como dato de la naturaleza. Para llegar a esta noción, se apoyó en nociones de corte existencialista ${ }^{2}$. Son estas nociones, (re)actualizadas y (re)visadas, algunos de los puntos de arranque de la filosofía de Butler en tanto filosofía de la libertad entendida como un exilio sin vuelta de las nociones de esencia y sustancia. Pero, antes de adentrarnos en este asunto, y siguiendo el rastro de las indicaciones de Hannah Arendt en $1964^{3}$, es decir, cuando afirmó que no existe ninguna experiencia de pensamiento allende la experiencia personal.

Las filosofías de Simone de Beauvoir y Judith Butler tienen como momento de emergencia dos revelaciones de índole personal. Así, si Beauvoir escribió la ineludible referencia feminista Le deuxième sexe (1949) después de superar lo que podríamos llamar el vértigo del papel en blanco y adentrarse en esta obra significa conocer su trayectoria personal ${ }^{4}$, Butler y la inflexión que supuso Gender trouble. Feminism and the subvertion of identity (1990) emergieron tras la relación de ideas

\footnotetext{
${ }^{1}$ Amorós, Celia, Diáspora y apocalipsis. Estudios sobre el nominalismo de Jean-Paul Sartre, Valencia, Alfons el Magnánim, 2000, pp. 37-38.

2 El 29 de octubre de 1945, Jean-Paul Sartre impartió una conferencia cuyo texto se publicaría un año después. Es ahí donde podemos encontrar una de las más precisas definiciones del existencialismo como corriente filosófica: "el existencialismo [es] una doctrina que hace posible la vida humana y [...] declara que toda verdad y acción implica un medio y una subjetividad humana", en Sartre, Jean-Paul, El existencialismo es un humanismo, Barcelona, Edhasa, 1946, 1999, p. 23.

3 Véase la reseńa sobre esta entrevista radiofónica en Zamboni, Chiara, "Intermedio. Inventar, agradecer, pensar", en El perfume de la maestra. En los laboratorios de la vida cotidiana, Barcelona, Icaria, 1999, 2004, pp. 22-28.

4 Sánchez, Cristina, Simone de Beauvoir: del sexo al género, Barcelona, Batiscafo SL, 2016, pp. 9-10.
} 
que eclosionó mientras veía un espectáculo de travestismo ${ }^{5}$ y reflexionaba sobre los avatares de su vida:

"Crecí entendiendo algo sobre la violencia de las normas de género: un tío encarcelado por tener un cuerpo anatómicamente anómalo, privado de la familia y de los amigos, que pasó el resto de sus días en un 'instituto' en las praderas de Kansas; primos gays que tuvieron que abandonar el hogar por su sexualidad, real o imaginada; mi propia y tempestuosa declaración pública de homosexualidad a los dieciséis años, y el subsiguiente panorama adulto de trabajos, amantes y hogares perdidos. Todas estas experiencias me sometieron a una fuerte condena que me marcó, pero, afortunadamente, no impidió que siguiera buscando el placer e insistiendo en el reconocimiento legitimador de mi vida sexual. Identificar esta violencia fue difícil precisamente porque el género era algo que se daba por sentado y que al mismo tiempo se vigilaba terminantemente" ${ }^{6}$

Por otro lado, es ya típico y recurrente recordar que El segundo sexo (1949) es el fruto, tal y como la filósofa explica en La force des choses (1963), del intento de responder a una pregunta, concreta y enfocada a sí misma, que formulara Sartre. Vale la pena la trascripción:

"[...] tenía necesidad de hablar de mí. Me gustaba L'âge d'homme de Leiris; me interesaban los ensayos, martirios en los que uno se explica sin pretexto. Comenzaba a pensar en eso, a tomar algunas notas y le hablé del tema a Sartre. Me daba cuenta de que se planteaba un primer problema: '¿qué es lo que había significado para mi ser una mujer?' [...] Miré y tuve una revelación: el mundo era un mundo masculino, mi infancia se había alimentado de mitos forjados por los hombres y de ninguna manera había reaccionado como si fuera un varón. Me interesé tanto que abandoné el proyecto de una confesión personal para ocuparme de la condición femenina en su generalidad. Iba a leer a la Biblioteca Nacional y estudiaba los mitos de la femineidad"

Sin embargo, dando una vuelta de tuerca más, podemos decir que el momento de motivación que articula El segundo sexo (1949) es uno que ahonda en una cuestión de identidad. Dicho de otro modo, cuando Beauvoir se esfuerza por responder a la pregunta del quién soy yo y, en efecto, se encuentra con un continente hundido,

\footnotetext{
5 El hecho de que la autora estadounidense haya afirmado que el travestismo es una ocasión para explicar la dimensión performativa del género, lo cierto es que aclaró que considerar tal acción "un paradigma de la acción subversiva o, incluso, como un modelo de la acción política sería un error, pues se trata de algo bastante diferente", en Butler, Judith, El género en disputa. El feminismo y la subversión de la identidad, Barcelona, Paidós, 1990, 2007, p. 27.

${ }^{6}$ Butler, Judith, El género en disputa, op. cit., pp. 23-24.

7 Beauvoir, Simone de, La fuerza de las cosas, Barcelona, Edhasa, 1963, 1987, p. 102. [La cursiva es nuestra]
} 
está decidiendo escribir su obra en aras de reflejar su propia identidad ${ }^{8}$. Antes de la revelación que le permitió hacer objeto de su pensamiento la situación objetivada de las mujeres, Beauvoir estaba convencida de ser una intelectual inmersa en el ámbito intelectual, esto es, el de la universidad y que, por ello mismo, se hallaba por encima de las limitaciones propias de los sexos. De hecho, en sus Memoires d'une jeune fille rangée (1958), explica que "solo imputaba a mi edad las privaciones que me infringían; sentí vivamente mi infancia, nunca mi femineidad" 9 .

Sea como fuere, y si bien en sus inicios llegase a afirmar una incredulidad importante respecto a los movimientos feministas, la pensadora francesa abandonó su postura intelectual inicial y participó de una manera activa, e incluso lideró, algunas vertientes del feminismo de los años setenta, como el Mouvement de Libération des Femmes (MLF).

De una manera sintética, podemos decir que mientras Beauvoir buscó las condiciones existenciales que posibilitaran para las mujeres la realización de la propia libertad, Butler apuesta por maximizar el potencial de vidas vivibles, esto es, ampliar las zonas del pleno reconocimiento, con el fin de que aquellas personas que no viven de acuerdo con las normas imperantes y binarias de género quepan en ellas.

\section{Sobre el arsenal conceptual existencialista y la disidencia de Beauvoir}

Es SABIDO QUE LA GRAN PREMISA DEL EXISTENCIALISMO se concreta en que la existencia precede a la esencia y Beauvoir dedujo de tal principio que la cultura es la esfera primordial para el análisis de los asuntos humanos. Que la existencia preceda a la esencia implica que el ser humano comienza por existir, se encuentra, surge en el mundo y, solo después, es capaz de definirse. El ser humano comienza, pues, siendo nada. Y, si lo humano no es delimitable antes de sus acciones, es claro que el concepto de naturaleza humana queda inhabilitado, porque la humanidad es lo que hace, y nada más. El ser humano remite a una tendencia incesante a algo que está más allá de sí mismo. Las nociones procesuales y abiertas son las únicas que podrían decir algo de lo que sea la humanidad. Así, en definitiva, el existencialismo deja atrás los planteamientos sustancialistas que, a lo largo de la historia, han apuntado a fijaciones conceptuales ante todo concretas y cerradas. No en vano, uno de sus puntos a atacar más notables es el concepto de esencia. Sartre explica esta condición de objetualidad en El ser y la nada (1943):

\footnotetext{
${ }^{8}$ Guerra, María José, "La mujer-filósofo o la más 'antinatural' de las criaturas. En torno a Simone de Beauvoir y a su obra El segundo sexo”, Revista valenciana. Estudios de filosofía y letras, no 7, 2011, pp. 132-133.

9 Beauvoir, Simone de, Memorias de una joven formal, Barcelona, Edhasa, 1958, 1981, p. 59.
} 
"[la] esencia de un existente no es una virtud enraizada en la profundidad de ese existente: es la ley manifiesta que preside a la sucesión de sus apariciones, es la razón de la serie [...] Pero, la esencia como razón de la serie no es sino el nexo de las apariciones, es decir, es ella misma una aparición" 10

Los atributos de la esencia son la identidad, la plenitud y la (con)sistencia. Es el modo de ser de los objetos, de las cosas no humanas que pueblan el mundo y que carecen de subjetualidad. Se trata del modo de ser del en-sí, un en-sí del que puede decirse que es, que es en sí y que es lo que es. A la luz de la cita recién expuesta, la esencia es el sentido del objeto y la razón de la serie de apariciones que lo develan. Dicho de otra manera, la esencia ve mermado su significado al de condición de un develamiento: es ser-para-develar y no ser-develado. Ser para develar, pero, nótese, siempre por un existente. De ahí que el siguiente concepto matriz del existencialismo, el de la existencia, quede primado en su relación con el de la esencia.

La existencia precede y significa la esencia y se refiere al modo de ser del ser humano. Así, es también posibilidad. Ex-sistir consiste en un desenvolvimiento relacional ex-tático hacia los objetos, entendidos estos como esencias. El ser humano, por su constitución de ex-sistente, escapa siempre a lo que es y se renueva continuamente. Entonces, la realidad humana es nada y ha de hacerse. El ser consciente existe o, lo que es lo mismo, es la ley del sujeto cognoscente. En tanto consciencia, la naturaleza misma del ser humano es algo así como existir en círculo: toda existencia consciente existe como consciencia de existir. Si la conciencia, tal y como prescribe el dictum fenomenológico, es siempre conciencia de algo, es claro que el existencialismo concluye que la conciencia misma no es nada, esto es, su estatuto ontológico es el del no-ser. Sea como fuere, la existencia, en tanto proyección, se asume ampliando en cada cumplimiento de ser la libertad y haciendo ser a través del ejercicio de la trascendencia: el ser humano siempre está más allá, orientado hacia otras cosas que sí mismo. Los pensamientos, miradas, etc., de la realidad humana, o sujeto, son trascendencia ${ }^{11}$.

La noción de proyecto es pertinente de una manera especial dado el sentido de este trabajo. Sobre todo, porque Butler afirmó que Beauvoir es una teórica que hizo del género un proyecto $y$, en este punto, es imprescindible recalcar que el proyecto es, ante todo, algo que no puede ser fijado. En clave etimológica, se explica como pro-iaceo: lo que se lanza más allá de sí hacia el ámbito abierto de posibilidades del que el ser humano, como existencia, se va apropiando y, en esa apropiación, se va

\footnotetext{
${ }_{10}$ Sartre, Jean-Paul, El Ser y la Nada. Ensayo de ontología fenomenológica, Barcelona, Altaya, 1943, 1993, pp. 16-17.

11 López Pardina, Teresa, "Simone de Beauvoir. Una filósofa del siglo XX", Servicio de Publicaciones de la Universidad de Cádiz, 1998, p. 38.
} 
realizando. Una realización que, dado que se identifica con la constitución siempre en proceso de su mismo ser, se alza como una responsabilidad radical. Por ser proyecto, por ser conciencia que, tal y como dice Sartre recuperando ecos hegelianos, "es lo que no es y no es lo que es" ${ }^{12}$, el ser humano es lo que se elije y elije lo que es: no tiene su propio ser como dado ni tampoco una esencia fija en cuya réplica se pueda constituir cada ejemplar concreto de la especie. Ha de hacerse ser eligiéndose a sí mismo. De hecho, debido a esta condición proyectiva, el ser humano es una superación de él mismo, hacia delante y en el mundo de los posibles. Pero téngase en cuenta, dadas las implicaciones importantes para los planteamientos de Butler, que se trata de una superación que nunca encuentra puerto donde atracar de una manera definitiva. Si el ser humano es, como dijera Sartre, un proyecto fallido de ser Dios, la humanidad entronca con un perpetuo fracaso en tanto efectivamente incapaz de sintetizarse con aquello a lo que apunta. Por supuesto, es desde este argumento donde el para-sí se hace y no es donde toma fuerza la gran premisa de Beauvoir de que "no se nace mujer: se llega a serlo" ${ }^{13}$. Porque la mujer no es. Asimismo, puesto que el hombre se hace no siendo mujer, la mujer queda rechazada y estigmatizada como lo otro absoluto. Por eso, El segundo sexo (1949) explica cómo la mujer es un ser que habita en la paradoja en mayor medida que el hombre: su hacerse apunta a la fijeza del ser por consistir en un hacer heterónomo y, en efecto, su remisión no es otro que el modo de ser de los objetos.

Respecto a las nociones de angustia y responsabilidad, cabe destacar que éstas han de analizarse de manera conjunta. Están relacionadas tanto en cuanto a su contenido como al lugar que ocupan en el entramado general de la filosofía existencialista. Si para la realidad humana, o para-sí, ser es elegirse, nada le llega de afuera. Y dando una vuelta de tuerca más, tampoco de dentro. Nada que pueda recibir o aceptar. Su abandono es absoluto en el sentido de que su necesidad de hacerse ser, hasta el más mínimo detalle, es total. Su constitución es de posibilidades, nunca de necesidades. El ser humano, criatura en permanente trance de desmayo o extinción cuya vida carece de sentido sustancial o genérico, remite, entonces, a una aventura singular que proyecta y mantiene a su costa, a expensas de su responsabilidad. De la angustia hay que decir que se define como una toma de posesión reflexiva de la libertad por sí misma, esto es, el modo de ser de la libertad como conciencia de ser. La angustia es el sentimiento de la absoluta libertad. O sea, el ser humano, a

\footnotetext{
12 Sartre, Jean-Paul, El Ser y la Nada, op. cit., p. 35.

${ }^{13}$ La famosísima cita dice que "no se nace mujer: se llega a serlo. Ningún destino biológico, psíquico, económico, define la imagen que reviste en el seno de la sociedad la hembra humana; el conjunto de la civilización elabora este producto intermedio entre el macho y el castrado que se suele calificar de femenino. Solo la mediación ajena puede convertir un individuo en Alteridad", en Beauvoir, Simone de, El segundo sexo, Madrid, Cátedra, 1949, 2000, p. 371.
} 
través de la angustia, se da cuenta de que es el ser por el cual los valores existen y que, como tal, es una entidad injustificada y sin excusas: la angustia manifiesta a la conciencia la libertad y, al mismo tiempo, le testifica la profunda responsabilidad en que consiste la existencia. La humanidad es, pues, el fundamento sin fundamento de los valores.

Si nos fijamos en la tensión que supone, por un lado, la absurdidad del ser pleno con su plenitud masiva y, por otra parte, la falta de ser de la realidad humana, es cierto que es fácil que brote la perspectiva de una conciencia desgraciada. Todo ello porque la distancia de sí es el sentido último de la existencia, algo así como una degradación perpetua de la coincidencia y una separación que no cesa. Ciertamente, las nociones que se emparentan a la falta de ser como condición humana pueden llevar a una concepción pesimista de la realidad humana. Recordemos, por ejemplo, que la condena a la distancia que arrastra el para-sí conlleva una condena más profunda y un hecho irreductible que conduce a aquel suspiro del "estamos condenados a ser libres" ${ }^{14}$. No solo el sujeto es una perpetua superación de sí mismo sino que se ubica en esa misma superación. Es clara la resonancia del "ser de lejanías" 15 de Martin Heidegeer y su Sein und Zeit (1927). Y, sin embargo, Beauvoir establece que "solo un ser efímero es capaz de encontrar lo absoluto en el tiempo" ${ }^{16}$.

En fin, profundicemos un poco más en la libertad, pues es el concepto más importante de la órbita del existencialismo. De todos los acercamientos a la realidad humana, y debido a las consecuencias argumentales de todos los anteriores, la libertad es aquello por lo que se define el ser humano. Pero, eso sí, la libertad entendida como exilio sustancial y, por tanto, como posibilidad permanente de ruptura nihilizadora respecto al mundo y a sí misma: la humanidad es libre porque está, originalmente, desarraigada de la masa del ser. De ahí que ser, para el para-sí, remita a nibilizar el en-sí en tanto lo que él no es. La libertad, más que un ser, es la nada de ser del ser humano: "la ausencia se define como un modo de ser de la realidad humana con relación a los lugares y sitios que ella misma ha determinado por su presencia" ${ }^{17}$. Además, hay que tener en cuenta que, antes que ingrediente del ser humano, la libertad es la propia textura de éste: humanidad y libertad coinciden. Y esta coincidencia es, a fin de cuentas, la razón por la que hay mundo: el mundo es un reflejo de la libertad humana y ésta desvela las esencias intramundanas trascendiendo el mundo hacia sus propias posibilidades. No hay más universo que el de la subjetividad humana, detrás de la cual no hay más que su propio abandono.

\footnotetext{
${ }_{14}$ Sartre, Jean-Paul, El Ser y la Nada, op. cit., p. 305.

15 Heidegger, Martin, El Ser y el Tiempo, Madrid, Fondo de Cultura Económica, 1927, 2001, pp. 53-63.

16 Beauvoir, Simone de, La fuerza de las cosas, op. cit., p. 74.

17 Sartre, Jean-Paul, El Ser y la Nada, op. cit., p. 305.
} 
Cualquier objeto o en-si que se ponga en frente de la mirada significadora del para-si depende, de una manera total, de la libertad sin límites que le constituye dada su condición consciente.

Es en ese sin límites donde encontramos una de las mayores disidencias del pensamiento de Beauvoir respecto a las obras satreanas. Aunque es claro que el utillaje conceptual existencialista es el marco de la filosofía de Beauvoir, sería un error afirmar que la obra de ésta constituye un fiel y acrítico seguimiento de las teorías de Sartre ${ }^{18}$. Es más, nuestra filósofa, gran conocedora del pensamiento de Merleau-Ponty en su Phénoménologie de la perception (1945), se aproximó a éste en aquellos planteamientos que le distanciaron de Sartre ${ }^{19}$. Entonces, la cercanía de Beauvoir respecto a Sartre es crítica y, por ello mismo, algunos de los conceptos más importantes de El segundo sexo (1949) gozan de independencia y algo así como de originalidad teórica. Por ejemplo, el concepto de situación en tanto posición en el mundo.

El Ser y la Nada (1943) establece que la situación es, solo, la condición de posibilidad de la libertad. Por eso "no hay libertad sino en situación y no hay situación sino por la libertad. La realidad humana encuentra [...] resistencias [que] no tienen sentido sino en y por la libre elección que la realidad humana es" ${ }^{20}$. Sin embargo, Beauvoir distingue dos aspectos de la libertad a tenor de estudiar críticamente la paradoja sartreana. Por un lado, la libertad entronca con la autonomía del sujeto que, en el ejercicio de su trascendencia, es asumida como responsabilidad individual. En este sentido, la libertad es absoluta pues "es la modalidad misma de la existencia que [...] toma por su cuenta lo que le viene de afuera; ese movimiento interior es indivisible y, por lo tanto, total en cada uno" ${ }^{21}$. Esto se debe a que "la humanidad es más que una especie: es un devenir histórico [y] se define por la forma en que asume la facticidad natural" ${ }^{22}$. Por otro lado, como segundo aspecto, la libertad es una figura que concreta las posibilidades: "desde el punto de vista de la libertad [...] como superación activa de lo dado, las situaciones no son equivalentes: ¿qué posible

\footnotetext{
${ }_{18}$ Nuestra postura en este asunto difiere de otras como la de Michèlle Le Doeuff, para quien "El segundo sexo es también un libro de amor y ella aporta a su canastilla de boda monogámica una confirmación singular de la validez del sartrismo: vuestro pensamiento me permite pensar la opresión femenina, vuestra filosofía me pone en el camino de mi emancipación”, en Le Doeuff, Michelle, El estudio y la rueca. De las mujeres, de la filosofía, etc., Madrid, Cátedra, 1989, 1993, p. 93.

19 Aquí es interesante mencionar que Merleau-Ponty pierde la simpatía de Sartre por su posición ante la relación de confrontación entre la Unión Soviética y los Estados Unidos y los efectos que, según él, tiene en la moral comunista. Sus puntos en común se cifran en las afirmaciones de que el tiempo es el sentido del ser y que toda elección de un fin es antes un proyecto de una posibilidad futura.

20 Sartre, Jean-Paul, El Ser y la Nada, op. cit., p. 514.

${ }^{21}$ Beauvoir, Simone de, El segundo sexo, op. cit., p. 479.

22 Ibid., p. 529.
} 
superación hay para la mujer encerrada en un harén?” ${ }^{23}$. De esta manera, Beauvoir desmonta algunas de las posiciones sartreanas, sobre todo las que postulan que las elecciones humanas son actos absolutamente libres: hay situaciones en las que la libertad no puede ejercerse, o no es sino una mistificación. La filósofa, pues, hace de la situación un espacio limitado de manera fáctica que condiciona el alcance de los fines que se propone un ser humano. O sea, la situación y la libertad no son conceptos indisociables como pretendiera $E l$ ser y la nada (1943). He aquí el núcleo que habilita a Beauvoir a resaltar y denunciar la injusticia, y no solo la mala $\mathrm{fe}^{24}$, de la subordinación existencial como condicionante de la situación de las mujeres. Por esta razón, Beauvoir explica el hecho de la complacencia en la alteridad que se puede observar en algunas mujeres mediante la analogía con el período infantil humano: los niños, si son juzgados, están justificados ${ }^{25}$.

Pero Beauvoir no solo desafía la ética sartreana de la autenticidad mediante el establecimiento de que existen condiciones objetivas de opresión ${ }^{26} \mathrm{y}$, en efecto, desculpabiliza a las mujeres cuyas vidas están encerradas en la forma de la inmanencia, esto es, dentro de los parámetros esenciales de los objetos. Mientras Sartre no dedicó ni una sola línea a la noción de la situación en su relación con lo corporal ${ }^{27}$, Beauvoir analizó la existencia de los seres humanos considerando a estos como seres concretos y encarnados en cuerpos sexuados ${ }^{28}$. Con ello, se alza una noción de sujeto que queda allende la absolutidad y la abstracción de la concepción de Sartre. Una concepción que, no debemos olvidar, le ha merecido el apelativo de el último cartesiano y, además, explica una acusación de Merleau-Ponty hacia el gran filósofo que recupera Beauvoir: Sartre fue incapaz "de encontrar el espesor del mundo" ${ }^{29}$.

Llegados a este punto, se hace imprescindible ahondar un poco más en Merleau-Ponty. El sujeto, o ser humano, lejos de remitir a un acto absoluto de creación que solo es reconocido en la indeterminación del futuro en tanto contingencia, es, ante todo, diálogo enlazado con el mundo. La existencia, ya no equiparable a la conciencia o a la creación absoluta, es experiencia-vivida. $\mathrm{O}$, dicho de otro modo, el ser humano es, según la Fenomenología de la percepción (1945), una estructura sim-

23 Ibid., p. 382.

${ }^{24}$ La mala fe puede entenderse como el trucaje de la libertad por la facticidad, en López Pardina, Teresa, "Simone de Beauvoir. Una filósofa del siglo XX”, op. cit., p. 13. De todas maneras, la falta ética e impostura ontológica que Beauvoir veía en rendirse y degradar al modo de ser de las cosas, a la inmanencia, lo que es humano y, por tanto, trasciende hacia la libertad, Butler la desplaza como necesidad de supervivencia.

25 Beauvoir, Simone de, Memorias de una joven formal, op. cit., p. 78.

${ }^{26}$ Guerra, María José, "La mujer-filósofo o la más 'antinatural' de las criaturas. En torno a Simone de Beauvoir y a su obra El segundo sexo", op. cit., pp. 131-146.

27 López Pardina, Teresa, "De Simone de Beauvoir a Judith Butler: el género y el sujeto", Revista de pensamiento contemporáneo, no 37, 2012, p. 102.

28 Sánchez, Cristina, Simone de Beauvoir: del sexo al género, op. cit., p. 11.

29 Beauvoir, Simone de, Memorias de una joven formal, op. cit., p. 84. 
bólica cuyos actos no son enteramente libres. El filósofo explica esta idea afirmando que "la opción que de nuestra vida hacemos siempre tiene lugar sobre la base de un cierto dato. Mi libertad puede desviar mi vida de su sentido espontáneo, pero por una serie de mutaciones, aceptándola, y no por ninguna creación absoluta" ${ }^{30}$.

Merleau-Ponty y Simone de Beauvoir comparten una concepción corporal de la subjetividad. Una subjetividad que se vuelve ininteligible al margen de su entrelazamiento mundano. No en vano, Beauvoir citó a este pensador para rescatar su definición de la existencia como "movimiento mediante el cual los hechos se asumen" ${ }^{31}$. Aparece, pues, una visión del ser humano más dialógica y más humilde cuya libertad se relativiza a tenor de sus posibilidades. No es un significador sin más, ni un creador sin nada a sus espaldas.

\section{A modo de conclusión. la reformulación butleriana}

DespuÉs de ACERCARNos al utillaje CONCEPTUAL de la filosofía existencialista, así como a algunas disidencias teóricas que se dieron en su seno, es claro que Butler tiene a este pensar del desarraigo a uno de sus principales compañeros de viaje. En particular, a la impronta antiesencialista y antifundacionista que el existencialismo implica. Por ello, podemos puntear algunos enclaves en aras de fomentar una reflexión de tipo conciliador.

En primer lugar, la manera en que el existencialismo concibió el "ser" como contraposición al sentido de proceso y apertura en que consiste la existencia es, en última instancia, lo que empuja a Butler a escribir que "la perspectiva de 'ser' algo [...] me ha producido siempre cierta ansiedad" 32 . En segundo lugar, si bien el existencialismo hizo del para-sí una realidad que intenta alcanzar al en-sí mientras se pierde a sí misma, o, dicho de otro modo, la existencia, la realidad humana o, en suma, el para-sí, se hace y se proyecta superando los modos esenciales propios de los objetos de estar en el mundo, esta superación entronca, dirá Butler, con un rechazo que se realiza mediante un movimiento de preservación. En otras palabras, lo uno queda habitado por lo otro, de una manera inevitable: habitado por ese otro que lo uno intenta negar para afirmarse ${ }^{33}$. No en vano, la obra de Butler es un continuo énfasis en la dependencia primaria humana. El yo, lejos de una sustancia

\footnotetext{
30 Merleau-Ponty, Maurice, La fenomenologia de la percepción, Barcelona, Planeta, 1945, 1993, p. 462.

31 Beauvoir, Simone de, El segundo sexo, op. cit., p. 71.

32 Butler, Judith, "Imitación e insubordinación de género", Revista de Occidente, no 235, 1991, 2000, p. 86.

33 Aunque no podemos detenernos en este asunto, destacamos que éste es el núcleo explicativo del concepto butleriano de afuera constitutivo. Es una clave en el estudio de lo abyecto que, además, se configura a partir de algunas ideas de la filósofa Julia Kristeva.
} 
encapsulada en sí misma, es un conjunto implicado de procesos, siempre con otros, lo que implica negar, en su Giving an account of oneself (2005), la posibilidad de distinguir "entre el otro y el yo en el corazón de mi identidad"34. A fin de cuentas, Butler desenmascara al sujeto moderno como una entidad ególatra con sueños de dominio que ha despreciado lo diferente y no ha reconocido su interdependencia. Un sujeto que, desde parámetros androcéntricos, ha permanecido ensimismado creyéndose poseedor de una naturaleza, es decir, de una anterioridad inocente que lo ha ubicado en un lugar -ilusorio- no contaminado por carga cultural alguna.

En tercer lugar, si el existencialismo sartreano hizo de la libertad la mismísima textura del ser humano con el fin de negar la libertad como facultad, ingrediente o componente, Butler reniega convertir la capacidad de acción de los sujetos algo que estos tienen. $\mathrm{Y}$ es que entender la libertad como propiedad implica una acepción ontológica cuyos principios son liberales. Además, cuando Butler escribe en Excitable speech. A politics of the performative (1997) que la libertad puede entenderse como "posibilidad de ser algo más o algo distinto de lo que ya hemos llegado a ser" ${ }^{35}$, resuenan los ecos de aquella fórmula sartreana tan conocida de que la libertad es lo que el ser humano hace con lo que han hecho de él ${ }^{36}$.

Y, para terminar, volvemos a un punto que ha orbitado este artículo, a saber, que Beauvoir y Butler comparten una comprensión de la subjetividad no tan disímil como podría parecer a primera vista, porque para ambas lo humano entronca con una ambigüedad procesual irresoluble en tanto indefinible y siempre lanzada más allá de sí misma. En este punto, la ambigüedad es condición de la mismísima subjetividad $^{37}$. Tal y como Beauvoir expone en su Pour une morale de l'ambigüité38 (1947), los seres humanos son libres, mas esta libertad está sujeta tanto a los condicionantes del mundo en que habitan como a la existencia de los otros. De ahí que la ambigüedad refiera a algo así como una contradicción insalvable ${ }^{39}$. Desde el ámbito de las normas sociales y culturales y a través del psicoanálisis, la ambigüedad es un potente marco de intelección de la teoría butleriana sobre el sujeto generizado, sujetado y, a la vez, habilitado para una acción resistente ${ }^{40}$ y que puede ser revo-

\footnotetext{
34 Butler, Judith, Dar cuenta de sí mismo. Violencia ética y responsabilidad, Buenos Aires, Amorrortu, 2005, 2009. p. 107.

35 Butler, Judith, Lenguaje, poder e identidad, Madrid, Síntesis, 1997, 2004, p. 206.

36 Véase Sartre, Jean-Paul, San Genet, comediante y mártir, Buenos Aires, Losada, 1952, 1967.

37 Esto conlleva, una vez culminada la reactualización de Beauvoir por parte de Butler y de su apoyo en textos foucaultianos, la tesis que las normas son efectos ambivalentes de la ley dada la doble dimensión de ésta: como censura y como formación.

38 Véase Beauvoir, Simone de, Para una moral de la ambigüedad, Buenos Aires, La Pléyade, 1947, 1972.

39 Sánchez, Cristina, Simone de Beauvoir: del sexo al género, op. cit., p. 43.

40 Burgos, Elvira, Qué cuenta como una vida. La pregunta por la libertad en Judith Butler, Madrid, A. Machado Libros, 2008, p. 114.
} 
lucionaria: no solo los sujetos tienen como momento emergente la sumisión, sino que, además, la emergencia de la subjetividad en la sumisión posibilita la acción del sujeto. Esta idea, ciertamente curiosa, emerge de una concepción paradójica del sometimiento. Paradójica en tanto ambigua. Vistas así las cosas es claro, entonces, que el concepto de existencia ambigua que Beauvoir desarrolló es nuclear a la hora de abordar los interrogantes y las consideraciones que Butler se plantea en relación a la filosofía política y moral que se relaciona, de una manera harto estrecha, con la configuración discursiva de las subjetividades. 


\section{REFERENCIAS BibLIOGRÁficas}

Amorós, Celia, Diáspora y apocalipsis. Estudios sobre el nominalismo de Jean-Paul Sartre, Valencia, Alfons el Magnánim, 2000.

Beauvoir, Simone de, El segundo sexo, Madrid, Cátedra, 1949, 2000.

Beauvoir, Simone de, Memorias de una joven formal, Barcelona, Edhasa, 1958, 1981.

Beauvoir, Simone de, La fuerza de las cosas, Barcelona, Edhasa, 1963, 1987.

Burgos, Elvira, Qué cuenta como una vida. La pregunta por la libertad en Judith Butler, Madrid, A. Machado Libros, 2008.

Butler, Judith, El género en disputa. El feminismo y la subversión de la identidad, Barcelona, Paidós, 1990, 2007.

Butler, Judith, "Imitación e insubordinación de género", Revista de Occidente, no 235, 1991, 2000, pp. 85-109.

Butler, Judith, Lenguaje, poder e identidad, Madrid, Síntesis, 1997, 2004.

Butler, Judith, Dar cuenta de si mismo. Violencia ética y responsabilidad, Buenos Aires, Amorrortu, 2005, 2009.

Guerra, María José, "La mujer-filósofo o la más 'antinatural' de las criaturas. En torno a Simone de Beauvoir y a su obra El segundo sexo", Revista valenciana. Estudios de filosofía y letras, $\mathrm{n}^{\circ}$ 7, 2011, pp. 131-146.

Heidegger, Martin, El Ser y el Tiempo, Madrid, Fondo de Cultura Económica, 1927, 2001.

Le Doeuff, Michelle, El estudio y la rueca. De las mujeres, de la filosofía, etc., Madrid, Cátedra, 1989, 1993.

López Pardina, Teresa, "Simone de Beauvoir. Una filósofa del siglo XX", Servicio de Publicaciones de la Universidad de Cádiz, 1998.

López Pardina, Teresa, "De Simone de Beauvoir a Judith Butler: el género y el sujeto", Revista de pensamiento contemporáneo, no 37, 2012, pp. 101-107.

Merleau-Ponty, Maurice, La fenomenología de la percepción, Barcelona, Planeta, 1945, 1993.

Sánchez, Cristina, Simone de Beauvoir: del sexo al género, Barcelona, Batiscafo SL, 2016. 
Sartre, Jean-Paul, El Ser y la Nada. Ensayo de ontología fenomenológica, Barcelona, Altaya, 1943, 1993.

Sartre, Jean-Paul, El existencialismo es un humanismo, Barcelona, Edhasa, 1946, 1999.

DOI: https://doi.org/10.15366/bp.2020.24.010

Bajo Palabra. II Época. No 24. Pgs: 197-212 
